\title{
Progressive multifocal leukoencephalopathy in patients with AIDS: detection of JC virus DNA in CSF and brain
}

\author{
C J Perrons, R J S Chinn, J D Fox, S B Lucas, M J G Harrison, R F Miller
}

\section{Case presentations ( $D r R$ F Miller) \\ Case 1}

A 56 year old right handed Caucasian homosexual unemployed laboratory technician was admitted as an emergency in March 1993 via the accident and emergency department, with the sudden onset of slurred speech, left facial weakness and falling to the right. On specific enquiry he denied loss of consciousness, visual disturbances or headache; he felt generally weak and tired and had no other symptoms.

He was first found to be HIV-1 antibody positive in April 1987 and participated in the MRC Concorde Study until March 1992, at which point he developed oral candidiasis and a mild peripheral sensory neuropathy: his CD4 count had fallen to $190 / \mathrm{mm} .^{3}$ At this time he began co-trimoxazole as primary prophylaxis against pneumocystis pneumonia and "open label" zidovudine. This latter medication produced neutropenia and it was stopped; he began dideoxyinosine (ddl).

On examination he was orientated in time and place but had a short attention span; he had dysarthria but no dysphasia. Neurological examination revealed left sided neglect, a left upper motor neuron seventh cranial nerve palsy and left sided weakness in both arm and leg. There was an extensor left plantar and also the palmar-mental and grasp reflexes were both brisk (suggesting a frontal lesion). Investigations revealed: haemoglobin $=12 \cdot 7 \mathrm{~g} / \mathrm{dl}$, WBC $=4 \cdot 1$ (neutrophils $=3 \cdot 3$ ) $\times 10^{9} / 1$; Urea and electrolytes and liver function tests were normal. Serum toxoplasma and syphilis serology and cryptococcal antigen (CRAG) were negative. Culture of blood was negative for bacteria, mycobacteria and fungi.

CT of the head showed a right frontal low attenuation lesion without enhancement and without mass effect. At lumbar puncture the cerebrospinal fluid (CSF) was clear and colourless; analysis showed protein $=1.82 \mathrm{~g} / \mathrm{l}$; no cells were seen. Gram, Auramine, India ink stains and culture for bacteria, mycobacteria, fungi and viruses were negative. DNA amplification, using the polymerase chain reaction (PCR) for Herpes simplex virus 1 and 2, cytomegalovirus (CMV) and varicella zoster virus DNA was negative. Empirical antitoxoplasma therapy was begun with sulphadiazine and pyrimethamine, but this produced a widespread maculopapular rash after 10 days of therapy and so it was stopped. MRI was performed.

\section{MRI scan (Dr R f S Chinn)}

This showed agenesis of the corpus callosum (an incidental finding). A focal region of high signal intensity was seen in the right frontal white matter on T2 weighted imaging (fig 1). This extended out into the gyral cores sparing the cortical grey matter. It also extended inferiorally along the white matter tracts through the internal capsule and crus cerebri into the right side of the pons. This lesion was of low signal intensity on $\mathrm{T} 1$ weighted imaging (fig 2). It did not enhance after the administration of intravenous gadolinium-DPTA. There was no mass effect associated with this lesion. There were further similar small lesions in the right cerebellar hemisphere and in the right temporal lobe. These appearances were most likely to be due to progressive multifocal leukoencephalopathy.

\section{Dr R F Miller}

On the basis of clinical presentation and MRI appearances it was planned to perform a brain biopsy in order to confirm the diagnosis. The patient was initially in agreement with this decision but, following informed consent, declined surgery. His condition subsequently deteriorated rapidly with difficulty swallowing and recurrent aspiration of fluids. Terminally

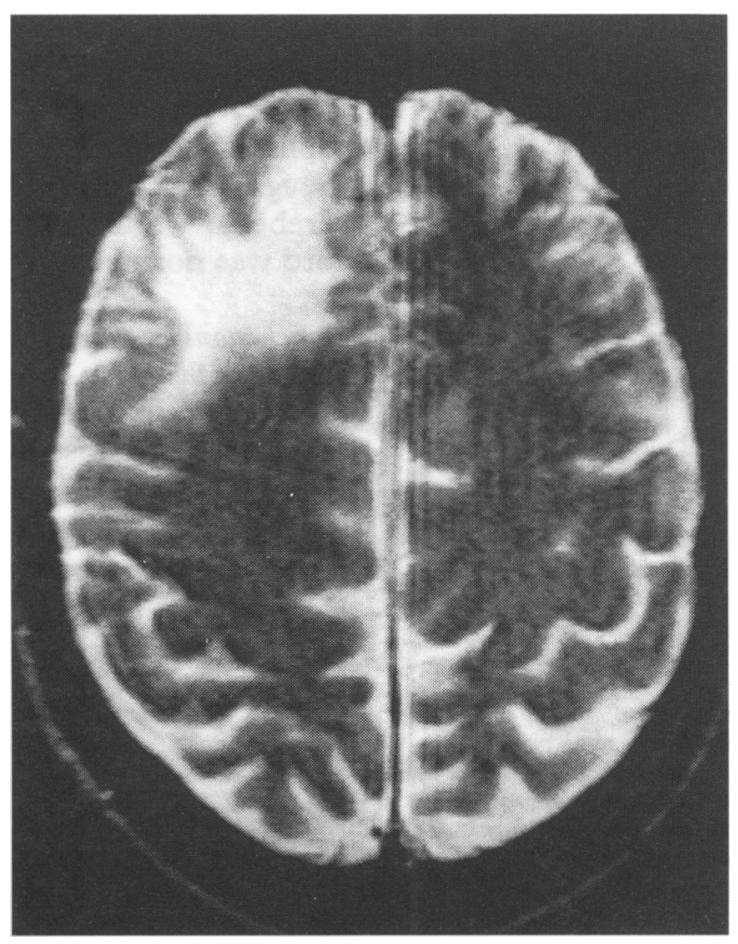

Figure 1 Case 1: T2 weighted MRI scan showing high intensity signal in the right frontal white matter. \\ Division of Virology, \\ Medical Microbiology \\ Department of \\ Department of \\ M J G Harrison \\ Department of \\ Medical School \\ R F Miller \\ Department of \\ Imaging, Middlese \\ W1N 8AA \\ R J S Chinn \\ Correspondence to: \\ Dr R F Miller, Departmen \\ of Medicine, UCLMS \\ 7 June 1994
}


Figure 2 Case 1: T1 weighted MRI scan showing low intensity signal (arrows) extending along the white matter tracts through the internal capsule.

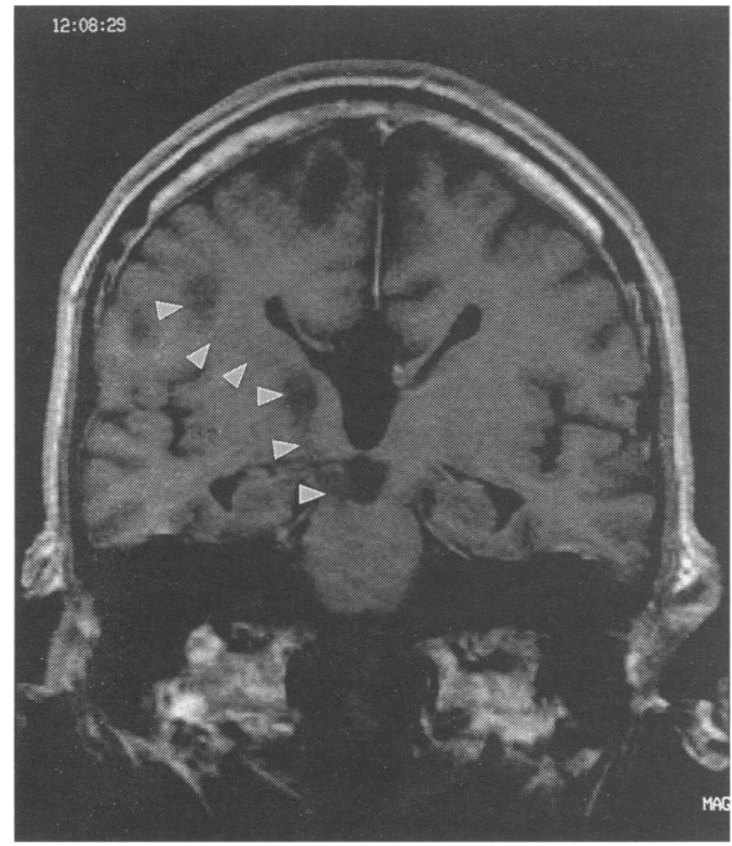

he was confused, disorientated and had a poor memory. A necropsy was performed.

\section{Pathology (S B Lucas)}

At necropsy, the patient was not wasted. There were blisters on the trunk and a widespread maculopapular rash. Internally, both trachea and lower oesophagus were severely inflamed, and the lungs (combined weight $2230 \mathrm{~g}$ ) were consolidated. The brain (weight $1370 \mathrm{~g}$ ) had the rare phenomenon of a congenitally absent corpus callosum (fig 3). Softening of the white matter was evident in the right frontal lobe, anterior right thalamus extending to the right cerebral peduncle.

Histologically, the skin lesion was erythema multiforme (due to a drug reaction). Whilst the tracheitis was associated with cytomegalovirus (CMV) the oesophagitis had no identifiable pathogen. There was also CMV adrenalitis. The lungs showed Gram positive coccal pneumonia. In the brain widespread progressive multifocal leukoencephalopathy (PML) was present not only in the grossly abnormal areas but also in the cerebellar white matter (figs 4,5 ). The spinal cord was normal.

\section{Conclusions of necropsy}

Major pathologies: 1. bacterial pneumonia, 2. progressive multifocal leukoencephalopathy, 3. congenital absence of corpus callosum.

Figure 3 Case 1: Coronal slice of brain. The corpus callosum is absent. The abnormal white matter of progressive multifocal

leukoencephalopathy is (as usual) difficult to depict in photographs when it has not progressed to frank necrosis.

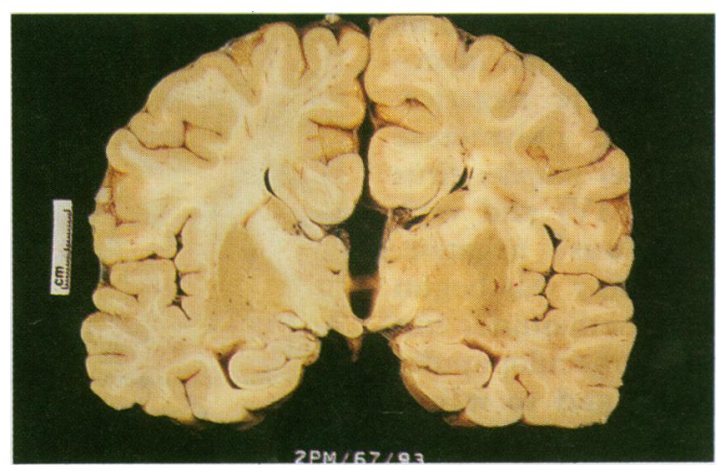

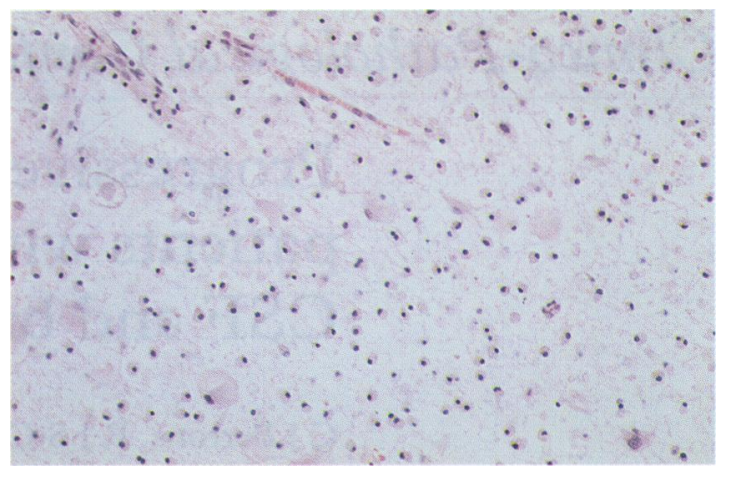

Figure 4 Case 1: Progressive multifocal

leukoencephalopathy in brain. The tissue is "empty" apart from microglial cells phagocytosing myelin debris. $(\times 400)$ (haematoxylin and eosin).

Minor pathologies: 1. CMV adrenalitis and tracheitis, 2. erythema multiforme due to sulphadiazine.

Case 2 ( $R$ F Miller)

A 32 year old right-handed Caucasian homosexual financial consultant was admitted to his local hospital in September 1993 with a four week history of clumsiness and weakness of the right arm and weakness of the right side of the face. In addition he reported poor memory and concentration; these symptoms were confirmed by both friends and family. In the two weeks before admission he had noticed progressive dysphasia and in addition difficulty in writing. He denied headache, loss of consciousness, auditory or visual problems and had no past history of note. He had lived and worked in the United States for the past ten years but more recently had lived and worked in Central Africa. He had multiple homosexual partners and had engaged in high risk sexual activity. He had never had an HIV test.

On examination at his local hospital, the neurological signs were of a right upper motor neuron seventh cranial nerve and a right twelfth nerve cranial palsy. There was no grasp or palmomental reflex. Tone was spastic and power was MRC grade 2 in the right arm. There was generalised hyper-reflexia with clonus of the right ankle. The plantar

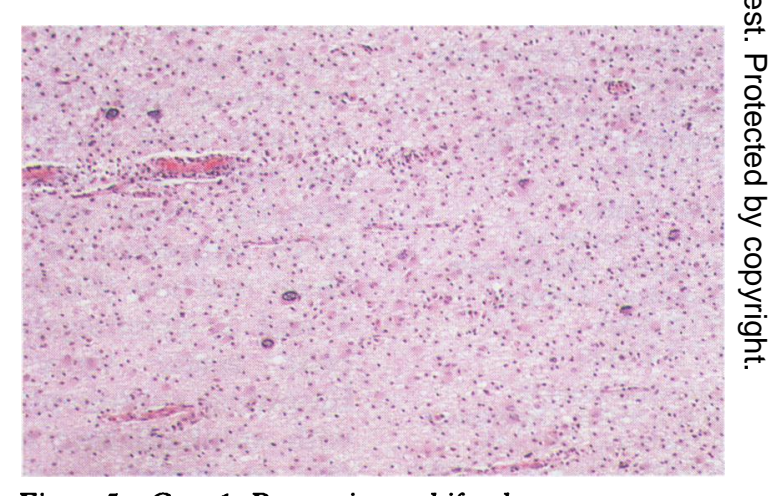

Figure 5 Case 1: Progressive multifocal

leukoencephalopathy in brain. Less severe lesion showing numerous large bizarre astrocytes characteristic of $P M L$. ( $\times 100)$ (haematoxylin and eosin). 
responses were bilaterally extensor. Investigations showed haemoglobin $=12 \cdot 8$ $\mathrm{g} / \mathrm{dl}$, WBC $=4 \cdot 7$ (neutrophils $=4 \cdot 3) \times 10^{9} / 1$; urea and electrolytes and a chest radiograph were normal. CT of the head showed diffuse cerebral white matter pathology. MRI showed widespread confluent and focal white matter signal change in the cerebrum and brain stem; in addition a right cerebellar-pontine angle tumour was seen and thought to be a schwannoma. At lumbar puncture CSF analysis showed protein $=0.58 \mathrm{~g} / 1$, no cells were seen; stain and culture for bacteria, mycobacteria, fungi and viruses were all negative. The patient was thought initially to have cerebral toxoplasmosis and began treatment with sulphadiazine and pyrimethamine. $\mathrm{He}$ was counselled about the possibilities of HIV infection; an HIV antibody test was positive.

The patient was transferred to the Middlesex Hospital for further investigation and management in October 1993. On admission the signs on examination were as above except that power in the right arm was now MRC grade 0 and in the right leg was MRC grade 2 . In addition the patient had very poor attention and was emotionally very labile. Investigations included an EEG, which showed focal but non-specific changes, and MRI.

\section{$M R I$ (Dr R f S Chinn)}

This showed a mass lesion in the right cerebello-pontine angle extending into the internal auditory meatus which enhances strongly. Even in the presence of HIV infection the lesion is most likely to be schwannoma. There were extensive areas of high signal intensity in the white matter of both parietal lobes on T2 weighted imaging (fig 6 ). The abnormalities extend into the gyral cores without involving the cortical grey matter. There was no associated mass effect. There were also multiple foci of high signal within the brain stem and cerebral peduncle. The regions of abnormality had low signal on $\mathrm{T} 1$ weighted imaging (fig 7). There was no enhancement after intravenous gadolinium-DPTA. These appearances are consistent with progressive multifocal leukoencephalopathy.

\section{Dr $R$ F Miller}

A repeat lumbar puncture was performed. CSF analysis showed protein $=0.6 \mathrm{~g} / \mathrm{l}$, no cells and stain and culture for bacteria, mycobacteria, fungi and viruses were negative. Cryptococcal antigen, toxoplasma and syphilis serology were negative in CSF and blood. DNA amplification for $H$ simplex virus, cytomegalovirus and varicella virus were negative. A CD4 count was $30 / \mathrm{mm}^{3}$.

It was thought on the basis of the MRI appearances and clinical presentation that the patient had progressive multifocal leukoencephalopathy; therefore his anti-toxoplasma treatment was stopped. In order to secure the diagnosis a brain biopsy was contemplated. The patient's condition rapidly deteriorated and he became increasingly drowsy, weak and incontinent. The biopsy was not performed

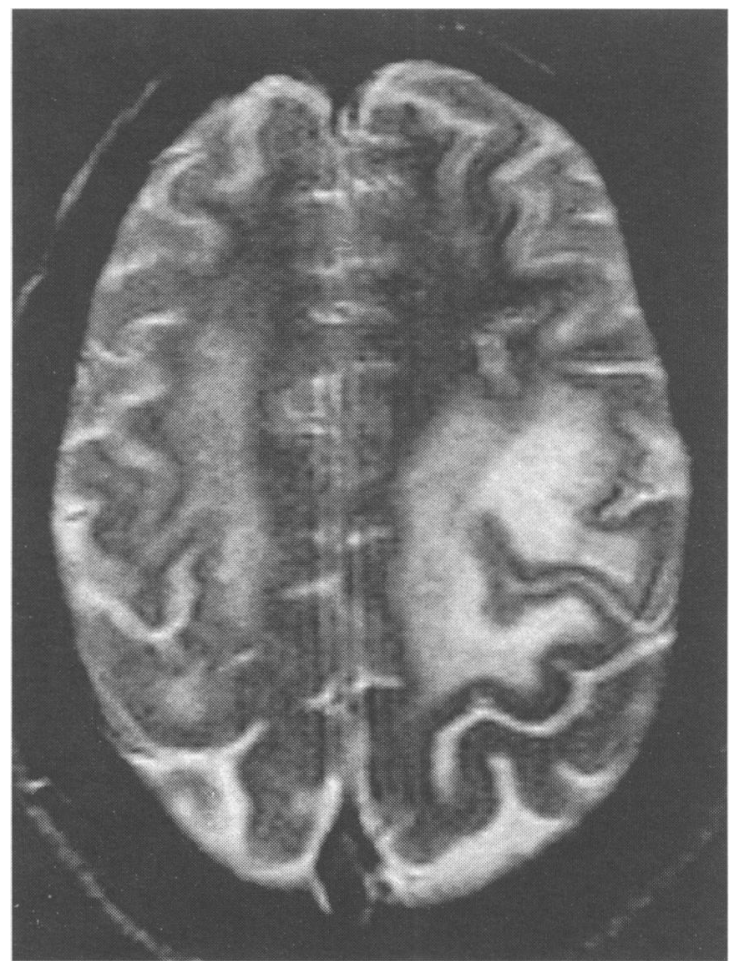

Figure 6 Case 2: T2 weighted MRI scan showing high signal intensity within the white matter of both parietal lobes; there is no associated mass effect.

and supportive care was given. Terminally the patient had profuse diarrhoea and died in early November 1993. Necropsy was performed.

\section{Pathology (S B Lucas)}

At necropsy the patient was thin, and had bilateral pneumonia (combined lung weight $980 \mathrm{~g}$ ) with recent right lower lobe infarction.

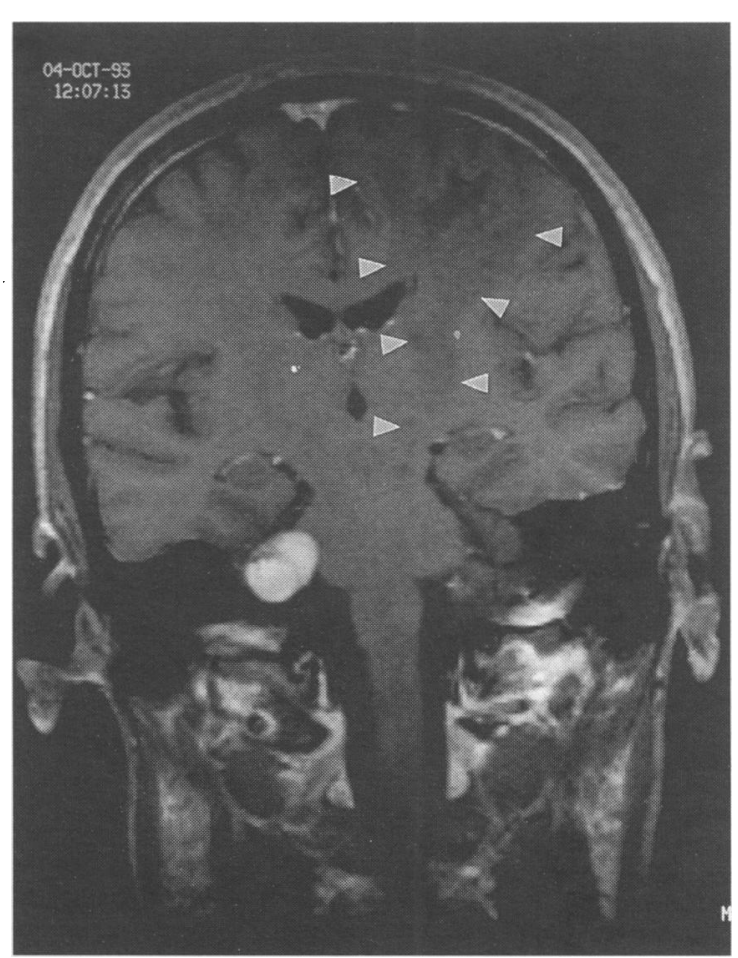

Figure 7 Case 2: Gadolinium enhanced T1 weighted image showing low signal intensity within the white matter extending down into the internal capsule (arrows). There is a strongly enhancing lesion in the right cerebello-pontine angle-a schwannoma. 
The colon showed pseudomembranous colitis, sparing the rectum. At the base of the brain (weight $1490 \mathrm{~g}$ ) was a yellow $2 \mathrm{~cm}$ diameter tumour on the right eighth cranial nerve. Cortical atrophy was absent but on slicing, ill-defined softening of the white matter extended from the left frontal lobe back to the left parietal lobe and into both occipital lobes.

Histologically, the lungs had purulent bronchopneumonia and haemorrhagic infarction (no emboli found). Pseudomembranous colitis was confirmed and CMV inclusions were not seen. The cerebral white matter lesions were PML associated with multinucleate giant cell encephalitis (fig 8). In the dorsal columns of the spinal cord there was early vacuolar myelopathy. The eighth nerve tumour was confirmed as a schwannoma.

\section{Conclusions of necropsy}

Major pathologies: 1. pneumonia, 2. PML and HIV encephalitis, 3. pseudomembranous colitis. Minor pathologies: 1. schwannoma, 2. vacuolar myelopathy.

\section{Virology (Dr C F Perrons and Dr F D Fox)}

CSF, peripheral venous blood and urine samples taken 13 weeks (case 1) and 4 weeks (case 2) before death, and a brain tissue sample obtained at necropsy were available from both patients and were screened for JC virus (JCV) DNA after amplification by the polymerase chain reaction (PCR). Approximately $2 \mathrm{~mm}^{3}$ brain tissue was ground using a mortar and pestle and digested in a buffer containing SDS and proteinase $\mathrm{K}$. Extracted brain tissue, CSF and urine samples were boiled and cooled on ice prior to addition to the PCR mixture. Peripheral blood mononuclear cells (PBMNC) were separated from heparinised venous blood using Ficoll-Paque (Pharmacia); PBMNC DNA was extracted and purified using phenol chloroform followed by ethanol precipitation.

"Nested" PCR was performed using two pairs of primers specific for the $T$ antigen region of JCV; the second (inner) pair was designed to amplify a portion of the first round PCR product. For each sample PCR was carried out in a Tris-based buffer containing $1.5 \mathrm{mM} \mathrm{MgCl}, 1.25 \mathrm{mM}$ of each deoxynucleoside triphosphate, $1 \cdot 25$ units of DNA polymerase (Ampli Taq, Perkin Elmer) and $100 \mathrm{ng}$ of each primer. Ten microlitres of

Figure 8 Case 2: HIVassociated giant cell encephalitis and progressive multifocal leukoencephalopathy. Associated with the enlarged astrocytes of PML are multinucleate giant cells (microglia). $(\times 200)$ (haematoxylin and eosin).
CSF, $1 \mu$ l of urine or brain extract and $\leq 2.0 \mu \mathrm{g}$ PBMNC DNA were added to the PCR mixture.

First round PCR was carried out, 4 minutes denaturing at $94^{\circ} \mathrm{C}$ followed by 35 cycles of $94^{\circ} \mathrm{C}$ for 1 minute [denaturing], $52^{\circ} \mathrm{C}$ for 1 minute [annealing] and $72^{\circ} \mathrm{C}$ for 1 minute [extension] with an additional 7 minutes extension in the last cycle (Perkin Elmer TC 1 thermocycler). After completion of the first round PCR $1 \mu \mathrm{l}$ of the DNA amplification product was transferred to a fresh PCR mixture containing the "nested" inner primers. The second round of PCR (25 cycles) was performed and these products were electrophoresed on agarose gel and detected by ethidium bromide staining.

Detectable JCV specific DNA sequences were identified by "nested" PCR in urine and brain extracts from both patients and CSF from case 1 (table 1). Peripheral blood mononuclear cell extracts from both patients did not contain detectable JCV DNA.

\section{Discussion (Professor $M \mathcal{F} G$ Harrison)}

Both these cases show the usual clinical presentation of progressive multifocal leukoencephalopathy (PML) with a rapidly evolving focal neurological deficit due to demyelination of hemispheric white matter. Headache, vomiting and depressed consciousness are rare as there is no mass effect even when the lesion affects a large part of the hemisphere. Neck stiffness, fever, and a CSF pleocytosis are rare because of the lack of a florid inflammatory reaction in the affected area. Epilepsy is unusual as this is predominantly a white matter disorder. ${ }^{12}$

There is now evidence that about $4 \%$ of patients with AIDS develop $\mathrm{PML}^{3}$ and that AIDS is now the underlying cause of 55 to $85 \%$ of PML. The disease was first described in 1958 in patients who had leukaemia and lymphoma. ${ }^{4}$ Immunosuppression has been an almost universal feature in subsequent cases; lympho-proliferative disorders have predominated as underlying causes but transplant recipients, patients on antineoplastic therapy and those with auto-immune diseases or with Whipple's disease have also been described as having PML. Cavanagh, in 1959, suggested that the role of immunosuppression was critical and that an opportunistic virus was therefore probably responsible. Virions morphologically identifiable as belonging to a papova virus were subsequently identified in the abnormal infected oliogodendroglia of patients dying from PML. The responsible virus was finally grown from the brain of a patient with PML whose initials were JC. ${ }^{5}$ The JC virus, as it was named, is the cause of a frequent childhood infection which is asymptomatic. By the age of six years, $50 \%$ of children have serocon-

Table 1 Detection of $\mathscr{F C V ~ D N A ~ i n ~ c l i n i c a l ~ s a m p l e s ~ b y ~}$ nested PCR

\begin{tabular}{lllll}
\hline Patient & CSF & Brain & Urine & Peripheral blood \\
\hline Case 1 & + & + & + & - \\
Case 2 & - & + & + & - \\
\hline
\end{tabular}


Table 2 Focal neurological deficit in patients with AIDS*

\begin{tabular}{|c|c|c|c|}
\hline Feature & $P M L$ & Toxoplasmosis & Cerebral lymphoma \\
\hline $\begin{array}{l}\text { Length of history } \\
\text { Motor weakness } \\
\text { (mono- or hemiplegia) }\end{array}$ & $\begin{array}{l}\text { weeks/months } \\
85\end{array}$ & $\begin{array}{l}<2 \text { weeks } \\
50\end{array}$ & $\begin{array}{l}2-8 \text { weeks } \\
40\end{array}$ \\
\hline $\begin{array}{l}\text { Speech dysfunction } \\
\text { (dys- or aphasia, dysarthria) }\end{array}$ & 30 & 10 & 40 \\
\hline $\begin{array}{l}\text { Visual deficits } \\
\text { (homonymous hemianopia } \\
\text { blurred vision, cortical } \\
\text { blindness, diplopia) }\end{array}$ & 30 & 10 & $?$ \\
\hline $\begin{array}{l}\text { Altered mental state } \\
\text { (personality change, } \\
\text { dementia, impaired memory, } \\
\text { reduced attention) }\end{array}$ & 25 & 60 & 50 \\
\hline $\begin{array}{l}\text { Seizures } \\
\text { Headache }\end{array}$ & $\begin{array}{r}5 \\
<5\end{array}$ & $\begin{array}{l}30 \\
55\end{array}$ & $\begin{array}{l}20 \\
30\end{array}$ \\
\hline Depression of consciousness & 1 & $5-30$ & 20 \\
\hline
\end{tabular}

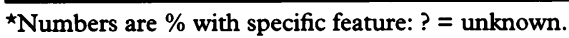

verted and by middle adulthood 80 to $90 \%$ of the population has been infected. ${ }^{6}$ Renal transplant patients and pregnant women commonly have JC virus in the urine. It has thus been suggested that the kidney is the site of latent infection. However, the genome of the virus obtained from the urine is not always the same as that in the brain and more recently Houff et $a l^{7}$ have shown the presence of JC virus in the B-lymphocytes of the marrow and spleen. It has therefore been suggested that activation of lymphocytes in immunodeficient patients leads to the presence of the virus in peripheral blood lymphocytes. It is then possible that HIV infected macrophages in the CNS produce cytokines that are chemotactic, bringing lymphocytes through the blood brain barrier, beginning infection of the brain with productive multiplication of JC virus in oligodendrocytes. The infected oligodendrocyte is eventually destroyed with release of virions which affect neighbouring oligodendrocytes; the disease therefore spreads like a bush fire. Damage to an oligodendrocyte can cause demyelination in as little as six or seven days.

The diagnosis of PML depends on the clinical picture of focal neurological deficits without evidence of raised intracranial pressure on imaging, on virological studies and ultimately on brain biopsy. ${ }^{2}$ Axial computed tomography (CT) brain scans, as in these cases, normally show low density areas within the white matter with little enhancement or mass effect. A few patients show a very faint peripheral enhancement. On MRI the lesions characteristically again show no mass effect and show no enhancement. ${ }^{8}$ The abnormal area is of low signal on T1 and on high signal on T2 showing a homogeneous appearance with a poorly defined edge. The shape of the lesion is scalloped because of the sparing of $U$ fibres at the grey matter/white matter interface. The spread of the lesion down the white matter pathway can often be eloquently shown on coronal T1 imaging. The posterior fossa is affected in $10-20 \%$ of cases; the majority show hemispheric white matter disease, often most obvious in the parieto- occipital area. An EEG may show non-specific slowing over the site of focal lesions but there are no diagnostic features. ${ }^{9}$ A focal EEG abnormality in a patient with AIDS and a developing hemiparesis, in the presence of a normal CT scan, would, however, be suspicious of PML and prompt MR imaging should be performed. Routine analysis of CSF is usually normal, but as already discussed, detection of JC virus-specific DNA sequences by PCR can support the diagnosis in the majority of cases.

The differential diagnosis of a focal neurological deficit, in a patient with AIDS, includes cerebral toxoplasmosis which usually has a shorter history, (less than two weeks), in contrast to several weeks or months with PML. While a focal deficit is commonly present with toxoplasmosis there is much more often an altered mental state with confusion and disorientation. Seizures are more common and depression of consciousness more usual. Headache is very common with toxoplasmosis and rare with PML. Lymphoma should also be considered in the differential diagnosis with a similar history of two to eight weeks. Altered mental state, seizures and depressed consciousness and headache are again more likely than with PML. Cerebral infarction, which is found at necropsy in up to $25 \%$ of patients with AIDS, also produces a focal neurological deficit but this is normally of a sudden onset and the imaging abnormality on CT or MRI follows a vascular distribution.

The imaging changes of high signal on $\mathrm{T} 2$ do not look like those of an enhancing toxoplasma abscess or lymphoma but can be confused with local encephalitis due to cytomegalovirus or HIV: HIV encephalitis is most unlikely to cause a hemiparesis so the combination of the clinical picture and imaging is usually discriminatory.

The prognosis after diagnosis of PML in HIV infected patients is poor with an average survival of only four months. ${ }^{23}$ Both the cases described here died within that period. Occasional cases have survived a much longer period of time $\mathrm{e}^{10}$ and in non-AIDS patients PML may remit if the immunodeficiency improves. It has therefore been suggested that aggressive antiretroviral treatment should be instituted if at all possible. In addition cytosine arabinoside ${ }^{11}$ and alpha interferon ${ }^{12}$ have both been advocated with anecdotal accounts of individual patients showing some improvement. Because of the side-effect profile of cytosine arabinoside it is usual to require brain biopsy confirmation of PML before using it. Trials are already underway in the USA and are planned in Europe, to see whether the anecdotal experiences can be confirmed in prospective studies.

1 Berger J, Kaskovitz B, Donovan Post M, Dickinson G. Progressive multifocal leuconcephalopathy associated with human immunodeficiency virus infection. Ann Intern Med 1987;107:78-87.

2 Sweeney BJ, Miller RF, Harrison MJG. Progressive multifocal leukoencephalopathy. $B r F$ Hosp Med 1993;50: 187-92.

3 Sweeney BJ, Manji H, Miller RF, Harrison MJG. Progressive multifocal leukoencephalopathy at the Middlesex Hospital 1989-91. Programme and Abstracts. Neuroscience of HIV infection

4 Astrom K, Mancall E, Richardson E Jr. Progressive multifocal leucoencephalopathy. Brain 1958;81:93-111. 
5 Padgett B, Walker D, Zu Rhein G, Eckroade R Cultivation of papova-like virus from human brain with progressive multifocal leukoencephalopathy. Lancet progressive mu

6 Padgett B, Walker D. Prevalence of antibodies in human sera against JC virus, an isolate from a case of progressive multifocal leucoencephalopathy. $\mathcal{F}$ Infect Dis 1973 127:467-70.

7 Houff S, Major E, Katz D, et al. Involvement of JC virusinfected cells from the bone marrow and spleen in the pathogenesis of progressive multifocal leucoenpathogenesis of progressive multifocal

8 Hansman Winterman ML, Donovan Post J, Berger JR Tate LG, Bell MD, Limonte LP. Progressive multifocal
The Tate LG, Bell MD, Limonte LP. Progressive multifocal
leucoencephalopathy in $47 \mathrm{HIV}$ seropositive patients; neuroimaging with clinical and pathologic correlation Radiology 1993;187:233-40

9 Farrell D. The EEG of progressive multifocal leukoencephalopathy. Electroencephalogy Clin Neurophysiol 1969; 26:200-5.

10 Berger J, Meuke L. Prolonged survival and partial recovery in AIDS-associated leucoencephalopathy. Neurology 1988;38:1060-5.

11 Portegies P, Algra P, Hollak C, et al. Response to cytorabine in progressive multifocal leukoencephalopathy in AIDS. Lancet 1991;337:680-1.

12 Berger J, Pall L, McArthur J, et al. Pilot study of recombinant alpha $2 \mathrm{a}$ interferon in the treatment of AIDSrelated progressive multifocal leucoencephalopathy. Neurology 1992;42(Suppl 3):257. 